Discussion Paper No. 675

VERTICAL INTEGRATION

IN THE U.S. CABLE INDUSTRY

\author{
Ayako Suzuki
}

November 2006

The Institute of Social and Economic Research

Osaka University

6-1 Mihogaoka, Ibaraki, Osaka 567-0047, Japan 


\title{
Vertical Integration in the U.S. Cable Industry*
}

\author{
Ayako Suzuki ${ }^{\dagger}$
}

October 18, 2006

\footnotetext{
${ }^{*}$ I am truly indebted to Joseph Harrington and Matthew Shum. Additionally, Gregory K. Leonard, Robert Moffitt, Steffen Reinhold, Katie Winder, and Tiemen Woutersen provided valuable input to this study. I would also like to thank participants from the presentations at the following institutions: the Bank of Japan, the International Christian University, the International University of Japan, the Johns Hopkins University, and Osaka University.

${ }^{\dagger}$ Institute of Social and Economic Research, Osaka University. Email: a-suzuki@iser.osaka-u.ac.jp. Tel: +81-6-6879-8581. Fax: +81-6-6878-2766. Address: 6-1 Mihogaoka, Ibaraki, Osaka 567-0047, Japan.
} 


\begin{abstract}
Theory shows that vertical integration has contrasting two effects, efficiency and foreclosure effects. This study empirically estimates the relative size of these two effects. Unlike previous studies, I focus on a single vertical merger in order to use a panel dataset, and estimate its average treatment effects on the several market outcomes. The findings suggest that there was a significant efficiency gain from the merger; the merged systems were found to carry affiliated networks more frequently; there was a larger price decrease in the merged markets. On the other hand, there was weak evidence of foreclosure. JEL classification: L10, L22, L40, C14.
\end{abstract}

\title{
1 Introduction
}

The causes of vertical integration and its consequences on market outcomes and consumer welfare have long been a controversial issue in economics and antitrust studies. According to theory, vertical integration can promote efficiency by eliminating successive monopoly markups, internalizing service, and mitigating contractual problems between firms. It can also facilitate the strategic practice of market foreclosure, whereby an integrated firm denies a rival access to markets in order to gain greater market power. The first effect results in lower prices, higher sales, and greater consumer welfare, while the second raises the prices of final goods, thereby harming consumer. Hence, "assessing the welfare effects of integration requires weighing the relative importance of the various effects" (Chipty 2001, pp.428).

This study empirically examines the relative size of these effects in order to better understand the welfare implications of vertical integration in the cable industry. This particular industry has experienced considerable backward integration between program service providers and cable system operators. The program service providers are upstream firms 
that provide cable networks to the cable system operators. The cable system operators are downstream firms that distribute the networks to consumers. The integration between these firms has raised concerns among anti-trust authorities, that consumers may be harmed if cable operators strategically foreclose competing programming networks. Such a possibility is of particular interest in the cable industry as program service providers usually do not have other means for distributing networks to consumers than via cable system operators, and each cable system faces little or no direct competition at the local level. As a result of such concerns, a restriction was proposed with the 1992 Cable Act. ${ }^{1}$ In order to assess the fairness of such a regulation, it is important to address the question of whether vertically integrated firms actually refuse to carry competing services on their distribution networks. However, this requires knowledge of the counterfactual outcome: What would have been the outcome if they had not been vertically integrated? This study examines this issue.

Unlike previous studies, the current study focuses on a single important vertical merger Turner Broadcasting and Time Warner - and compare outcomes before and after the merger. This is opposed to previous studies that compare merged and non-merged cable systems at a point in time; here I also examine the same systems before and after the merger. Using panel data enables me to estimate a dynamic response of the industry to the merger. Furthermore, differencing outcomes across two time periods eliminates selection bias problems in terms of unobservables when they are time constant. Since participation in a merger is non-random, I adopt a non-experimental matching strategy to estimate the average treatment effect of the merger. Specifically, I employ the recently developed bias-adjusted matching method by Abadie and Imbens (2002). 
The analysis shows that there was a significant efficiency gain from the merger. The merged systems carried affiliated networks more frequently than the non-merged systems, and the newly affiliated networks in the merged markets increased their numbers of subscribers to a greater than those in the non-merged markets. These findings confirm the evidences found in the previous studies such as Chipty (2001) and Waterman and Weiss (1996). In addition to these previous evidences of the efficiency gain, the current study finds a larger price decrease in the merged markets. Furthermore, unlike the previous studies, the systems' dynamic response suggests that there is weak evidence of foreclosure.

The paper is structured as follows: the next section describes the structure of the US cable industry. Section 3 reviews the relevant theories and the previous empirical studies of vertical integration. Section 4 describes the econometric method and data. The results are shown in Section 5 with an extensive discussion and Section 6 concludes the paper.

\section{US Cable Industry}

In the industry, upstream firms are program service providers. They produce their own programming and/or acquire programming produced by others, and package and sell them as a network or group of networks to cable system operators for distribution to consumers. Under program service providers are downstream firms or cable system operators. They choose the number, the types, and the brand of networks to carry, set prices and sell to consumers in franchise areas. All operators sell a bundle of basic cable services for a single price per month, and most sell larger bundles of basic cable services, called extended basic services, and a la carte premium movie and sports services. Cable operators range in size from single-system cable operators with only a few dozen subscribers to Multiple System 
Operators (MSOs) that own many systems and serve millions of subscribers. Cable services are furnished in local franchise areas by one or two cable systems, and consumers cannot switch to another system that does not offer service within that area. This division of the industry into a large number of independent local markets makes the industry an ideal setting for our empirical study. Most franchise areas are in fact served by only one cable system and this deepens the concern for foreclosure.

During the last decade, cable operators have continued to consolidate and develop new ownership interests in program service providers. Hence, vertical integration observed in this industry is backward integration. More than 30 percent of satellite-delivered national programming networks have been vertically integrated during the last decade. ${ }^{2}$

The anti-trust concern is that vertically integrated cable operators may strategically favor their affiliated networks to the disadvantage of unaffiliated networks, either by the exclusion of rival networks from their service or, if the rivals are carried, by preferential pricing and promotion of their own networks. Such strategy possibly increases sales (viewership) of the integrated networks within the operators' franchise areas and can ultimately benefit the integrated networks in unaffiliated franchise areas as rivals lose their competitiveness and possibly exit from the business. Hence, vertical integration may soften competition and harm consumers. On the other hand, vertically integrated firms may enjoy efficiency gains; theory shows that vertical integration eliminates vertical externalities; it may reduce cost of negotiation between program services and cable operators. Consequently, the effect of vertical integration in this industry is ambiguous. The purpose of this study is to clarify the relative size of these efficiency and strategic effects. 


\section{Theory and previous empirical studies}

\subsection{Theory}

Theories of vertical integration show that vertical integration has contrasting two effects: welfare improving efficiency effect and anti-competitive "foreclosure" effect.

Neoclassical theories explain vertical integration as a response to pre-existing market power problems. Pre-existing market power problems include various forms of vertical externalities. These theories show that vertical integration internalize externalities and results in lower consumer prices, higher sales, and higher trade of inputs. ${ }^{3}$ Organizational economicsbased theories show that vertical integration reduces transaction costs - that is the direct costs of writing, monitoring and enforcing contingent contracts as well as the costs associated with ex ante investment and ex post performance inefficiencies. Vertical integration thus results in higher ex-ante investment and higher trade of input. These are "efficiency" effects of vertical integration.

Market foreclosure encompass commercial practices that reduce buyers' access to suppliers or limit suppliers' access to buyers. The concern here is that vertically integrated cable operators may refuse to carry unaffiliated cable networks in their franchise markets. ${ }^{4}$ Theory shows that firms vertically integrate in order to monopolize their market. As a result of monopolization, the total quantity being supplied will fall, and the price consumers pay will rise. ${ }^{5}$ These are "foreclosure" effects of vertical integration.

It has been also shown that contracts such as exclusive dealing form barriers to entry. Such contracts force new upstream firms to set up their own distribution networks. Correspondingly, new upstream firms are less inclined to enter the market. Downstream 
foreclosure due to vertical integration will act in a similar fashion (Aghion and Bolton 1987). This theory predicts that in addition to higher prices, there are less entrants in vertically integrated upstream markets.

\subsection{Empirical literature}

There is little research that has empirically examined the relative importance of these various effects of vertical integration. ${ }^{6}$ Due to data availability, studies have concentrated on the cable industry (Chipty (2001), Waterman and Weiss (1996)), and the gasoline industry (Vita (2000), Gilbert and Hastings (2001)). The results from these studies are consistent with either a foreclosure or an efficiency theory of vertical integration. For example, in her exhaustive study in the cable industry, Chipty (2001) finds that vertically integrated cable distributors are more likely to exclude rival cable programming networks and favor their own affiliated networks. Overall, however, consumers are not harmed by this behavior, since the resulting changes in prices and product variety appear either not to harm or to benefit consumers overall. Waterman and Weiss (1996) examine the same issues for premium cable networks and find extensive evidence of exclusionary behavior on the part of vertically integrated firms. They find little evidence of any downstream price effects but do find that sales (i.e., penetration) are higher for affiliated programming services than for non-affiliated programming services. This suggests that vertical integration leads to increased downstream sales efforts with regards to distributor-owned programming services.

My study departs from previous studies in its use of econometric methods and data. Specifically, I employ a non-experimental matching strategy as opposed to Ordinary Least Squares (OLS) or heavily parameterized binary choice models (such as Probit or Logit), such 
as have been used in previous studies. The method used here may be preferable to those regression estimators when there exist differences in the covariate distributions for treated

and control groups. I will show this is likely to be the case here, as the mean values of covariates differ a great deal across the two groups. Furthermore, I focus on a single vertical merger and use panel data that consists of the year before and the year after the merger. This is opposed to previous studies, which make use of cross sectional data. Differencing variables across these two time periods eliminates the problem of selection bias in terms of unobservables, when unobservables are time constant. Using panel data also enables me to estimate the dynamic response of the industry to the merger.

The next section describes the econometric method used and the data.

\section{Econometric Method and Data}

Recently there has been much interest in and studies on the econometric method used for estimating the effects of active labor market programs. The conventional impact of interest is the average impact of the treatment, or the indicator of whether an individual participated in such an program or not. With experimental data, this average effect of the treatment can be obtained by comparing the sample averages of the treated and the control groups. Such experimental data may, however, be difficult to obtain in reality. Hence, the recent econometric literature has explored strategies for using non-experimental data and developed methods for estimating the average treatment effect under the unconfoundedness assumption

- "the assumption that the receipt of treatment is independent of the potential outcomes with and without treatment if certain observable covariates are held constant" (Imbens 2004). 
The application of such econometric methods should not be limited to labor markets. In this study, I estimate the average effects of a merger or a binary treatment of whether a cable system is vertically integrated or not, on downstream market outcomes.

\subsection{Treatment}

The treatment event here is the 1996 merger between Turner Broadcasting and Time Warner. This merger was between one of the biggest cable programming firms and one of the biggest cable operators. Turner Broadcasting is a major producer of news and entertainment programming; likewise, a provider of these programming for the basic cable industry. It is home to an array of cable TV networks, among them, multiple CNN news properties, entertainment networks such as TBS Superstation (TBS), Turner Network TV (TNT), the Cartoon Network (TOON), and Turner Classic Movies (TCM), and specialized networks such as Turner South and Boomerang. After the merger, these networks were owned by the new merged company. For convenience, I call this new merged firm Turner-Time-Warner. The merger was value at $\$ 7.5$ billion.

Initially, the merger faced the opposition of the Federal Trade Commission (the FTC), as there were concerns regarding anti-competitiveness in the cable industry. Tele-Communications Inc. (TCI), the biggest cable operator, owned 21 percent of Turner, and would have owned roughly 9 percent of the merged company. Regulators were concerned that this direct link would reduce TCI and Time Warner's incentives to compete against one another. The merger was approved on July 17, 1996, after the companies agreed to amendments limiting the role of the major shareholder TCI in the merged company, and a pledge that Time Warner would act in a non-discriminatory manner toward rival cable operators and programmers. ${ }^{7}$ 
The advantage of using this case for our study is that it caused ownership movements among many networks with different characteristics. Networks sold in this deal, such as TNT, TBS and CNN Headline News, are well-established popular networks (established in 1983, 1976 and 1982 respectively), while the TOON and TCM were relatively new networks (established in 1992 and 1994). Such variation is, in fact, instrumental to our analysis. Furthermore, the genres represented by CNN, TOON, and TCM are clearly defined ones ('news', 'children networks' and 'movies' respectively), thus making it feasible to measure the degree of competition these networks are facing.

As a result of this merger, all the cable systems that were owned by Time Warner in 1995 are now vertically integrated with Turner Broadcasting. In addition to this are some cable systems purchased by Time Warner after the merger occurred. These systems were not owned by Time Warner in 1995, but were owned by it in 2000; hence they have become vertically integrated with Turner Broadcasting. I exclude these cable systems from the treated group and limit the group for the systems that were already owned by Time Warner in 1995. The definition of treatment depends on the question of interest; the reason I exclude the systems owned by Time Warner after 1996 is because the pre-and-post difference of market outcomes for these cable systems may reflect more than the effect of the vertical merger. Change in their behavior might be due, not only to being integrated with Turner Broadcasting, but due to becoming owned by Time Warner and gaining horizontal market power. In order to assess the pure effect of vertical integration, I define my treatment such that the treatment status is 1 if a system is vertically integrated with Turner Broadcasting without changing ownership during the examination period. 


\subsection{The Data}

For this study, I use two main data sources: The Television and Cable Factbook and the U.S. Bureau of the Census: City and County Data Book. The Television and Cable Factbook compiles survey responses from all of the existing cable franchises. For each cable franchise in the United States, the data contains information on the system's owner, the date franchise was awarded, the total miles of cable planted, its channel capacity and the number of homes with access to cable (referred to as homes passed) within the system's franchise area. It also contains a description of the system's program offerings, its monthly prices and the number of subscribers for each cable service. I use the volumes for 1996 and 2001 of the Factbook, which provide data for 1995 and 2000 respectively. ${ }^{8}$ In this study, the data from the eight states is available: New York, North Carolina, New Hampshire, Ohio, Mississippi, Wisconsin, Florida, and Massachusetts. ${ }^{9}$ I thus have 1391 cable systems to examine, with the number of observations in the treated group (i.e., the number of merged cable systems) being 348 .

Table 1 represents the definition of our dependent variables: four outcome variables, five indicator variables of Turner Broadcasting networks, two indicator variables that represent the networks partially owned by Time Warner, ${ }^{10}$ and eleven indicator variables that represent the rival networks of the Turner Broadcasting networks. The differences between 1995 and 2000 of these variables are used. Table 2 shows the summary statistics of these dependent variables. Treated and Control are the mean values in the treated and controlled groups respectively. DID refers to the difference-in-differences treatment effect on the treated group without controlling for the covariates. It can be seen that, on average, per-network prices decreased, penetration rates increased, and the number of Turner Broadcasting networks 
increased in both the merged (treated) and non-merged (controlled) markets. The degree of such change differs between the merged and non-merged markets. In the merged markets, the per-network price decreased less while the penetration rate and the number of networks increased to a greater extent than was the case with the non-merged markets. Such differences are statistically significant for the number of Turner Broadcasting networks and that of non-Turner networks. Every Turner Broadcasting network increased its national market share during this period. ${ }^{11}$ All of the rival networks increased their national market share as well. The DID estimator shows that most of these changes were affected positively by the merger.

Turning to covariates, the matching variables $X$ can be partitioned into two sets: $X=$ $(V, Z)$, where $V$ are variables in the outcome equations and $Z$ are variables in the participation (merger) equation; $Z$ variables determine the treatment.

To identify the variables $V$ that affect the downstream outcomes in the cable industry, I modify the structural model of Waterman and Weiss (1996); while Waterman and Weiss focused on the pay services of cable systems, I focus on the basic services, given this feature of Turner Broadcasting. ${ }^{12}$ The model induces the equations of the downstream outcomes, such as price, network choice and the number of subscribers, which depend on the ownership characteristics, the non-input cost, the capacity to carry networks, demographic demand factors and some unobservable variables such as managerial skill and structure. I use proxies for these observable factors as covariates $V$ and most of them overlap with the covariates used in Chipty (2001). ${ }^{13}$

The variables $Z$ should be carefully considered. As discussed in the next subsection, the treatment status depends on whether a cable system is owned by Time Warner. Cable 
systems decide whether or not to sell itself to Time Warner and Time Warner decide whether or not to purchase them. I assume such decisions depend on the system's profitability. The system's profitability should be again determined by the observable and unobservable factors discussed above because profit depends on the market outcomes. Therefore, I again use the proxies for the observable factors discussed above for the $Z$ variables. Inasmuch as in the participation equation these variables should be determined pre-treatment, the 1995 data are used for the $Z$ variables. On the other hand, the difference between 1995 and 2000 is used for the $V$ variables. Table 3 summarizes the final matching variables. ${ }^{14}$

More specifically, Table 4 shows the summary statistics of the matching variables with the mean values of the treated group and the controlled groups respectively. As can be seen, the two groups have statistically different characteristics pre-treatment. For example, the mean values of owner size, density, homes passed, and length of plant are much different between the two groups. Assuming that these variables proxy system size and efficiency, the treated group consists of those systems that are larger and more efficient. On the other hand, the demographic characteristic of the percentage of young viewers is not so different between the two groups.

\subsection{The Estimator}

What we are interested in is the average effect of the vertically integration on market outcomes in the integrated markets. Because each observation can receive only one treatment for each time period, one of the outcomes in the two states is not observed. Missing data is a fundamental problem in any impact evaluation study. With experimental data, this average

effect of the treatment can be obtained by comparing the sample averages of the treated 
group with those for the control groups. Upon first glance, the treatment-i.e., the indicator of whether a system has been vertically integrated or not - seems to have the feature of experimental data: cable systems happen to find themselves to be vertically integrated because the decision for vertical integration was made by cable operators, and not by individual cable systems. ${ }^{15}$ However, while the decision to vertically integrate is exogenous to individual local cable systems, the decision as to whether or not to be owned by large MSO is not. Whether or not to sell one's company to an MSO is the decision of a cable system, and whether to purchase a cable system is the decision of a cable operator. Since such decisions may depend on the characteristics of the systems, an endogeneity problem arises. ${ }^{16}$ For this reason, I adopt a non-experimental strategy for estimating the average treatment effect of the merger.

The simplest non-experimental strategy, arguably, would be to use a linear regression estimator. Such regression estimators impute missing potential outcomes using the estimated regression function. However, simple regression estimators may be very sensitive to differences in the covariate distributions for treated and control groups, as they rely heavily on extrapolation (see Imbens (2004), pp 13). As seen in Table 4, our covariates have significantly different mean values across the groups. Arguably, the linear estimator will suffer from these biases.

Matching estimators also impute missing potential outcomes, though only by using the outcomes of the opposite treatment group that have the closest characteristics. Using this method, two groups are nonparametrically matched for the common values of $X_{i}$, or the observed characteristics of a market $i$, and the outcomes of the matched-comparison group are used to construct the counter-factual outcomes for the treated individuals such as should 
correspond to the outcomes had they not received treatment. In this sense, the estimators rely less on extrapolation, and biases from them should be smaller. Significantly, our data set has many observations for the controlled group, one of the reasons favoring the marching method used here. ${ }^{17}$

The matching estimators, however, generate biased results if the matches are not exact. Abadie and Imbens (2002) shows that the bias of the matching estimator may dominate the variance if the dimension of the covariates is large, and suggests the additional bias correction. ${ }^{18}$ Since I have many continuous covariates, such a bias could prove serious to this study. ${ }^{19}$ I therefore follow their bias adjusted matching estimator, which adjusts the means of outcomes in the set of matched observations by differences in the covariates between this matched observation set and the overall comparison group.

The bias-adjusted matching estimator, like other non-experimental strategies, assumes unconfoundedness - that is, it assumes that the receipt of treatment is independent of the potential outcomes with and without treatment conditional on observable covariates. This assumption does not hold when there are unobservable differences between the treated and control groups that affect the outcomes. Factors such as a cable system's managerial and sales skills seem to violate this assumption. To mitigate this problem, I incorporate into the matching method the difference-in-differences method. If the unobserved factors are time invariant, the difference-in-differences matching estimator can eliminate biases due to such factors. Only bias caused by differences in time variant unobservables between the two groups cannot be wiped out using this method. It seems to be extremely difficult to find the appropriate instrument variables in this case: if participation in the merger depends on each cable system's profitability, any variable affecting the merger decision should also affect the 
outcome variables. To mitigate bias due to time-variant unobservables, I conduct an exact match on State, as this should capture transitory shock if they are at the state level.

\section{$5 \quad$ Empirical Results}

Table 5, 6 shows the estimated average impact of the merger between Turner Broadcasting and Time Warner on Time Warner's downstream markets. Treatment is defined here as "being vertically integrated with Turner Broadcasting without changing its ownership by Time Warner". The average treatment effects on the treated group are estimated using the bias-adjusted matching method with difference-in-differences. For matching, it uses the Euclidean norm to measure the distance between the different values for the covariates after normalizing the covariates so that they have zero mean and unit variance. The units are exactly matched on the state. For the bias adjustment, the regression uses all of the matching variables. Standard errors are estimated using the variance estimator from Abadie and Imbens $(2002)^{20}$.

The problem with matching methods remains that there is no theoretical justification for determining an optimal number of matches. Abadie and Imbens (2002) show that a simple matching method produces radically different estimates when the number of matches changes. If we increase the number of matches, the quality of the matches goes down, while the efficiency loss decreases. ${ }^{21}$ In general then, there is a trade off between efficiency and biasedness when we increase the number of matches, although Abadie and Imbens show that the bias-adjusted matching estimator demonstrates much more robust behavior when the number of matches changes. In their Monte Carlo simulation, Abadie and Imbens show that the bias-adjusted matching estimator performs best when the number of matches is around 
4 to 16 , in terms of the root-mean-squared-error and the median-absolute-error. ${ }^{22}$ Here, I $^{2}$ show the results with 4 to 10 matches. The results with different numbers of matches are also available.

\subsection{The Efficiency Effect}

The first category of Table 5 shows the treatment effects on the outcomes of the downstream market - that is, changes in the number of Turner Broadcasting networks included in the basic/extended basic cable services, in the number of non-Turner Broadcasting networks, in the price per network and in the penetration rate. The second category of Table 5 shows the average treatment effects on the affiliated networks. The first five networks are Turner Broadcasting networks, and thus became owned by the merged cable operator (Time Warner) as a result of the merger. The last two networks, Comedy Central and Court TV, are not Turner networks, but were owned by Time Warner prior to the merger.

Except for the news channel, CNN, which was subjected to special restrictions by the FTC, the signs of the average treatment effects are all as predicted by the efficiency theories. That is, the treatment effects on the affiliated networks and those on the number of Turner networks are positive (except TNT with $\mathrm{M}=4$ ), implying that the merged firm substitutes more towards the inputs of the affiliated upstream firms. Similarly, as consistent with any efficiency theory, the treatment effect on consumer price is negative, while that on the penetration rate (i.e., sales) is positive.

The positive average treatment effects on the affiliated networks are significant for the TBS Superstation and Turner Classic Movies, at least at the 5-percent level. Specifically, the result shows that the TBS Superstation increased its market share by 11.3-12.7 percent more 
in the merged markets than in the non-merged markets. The relatively new network, Turner Classic Movies, also benefited from the merger. The market shares of this network increased by about 9.3-14.5 percent more. Reflecting this, the average treatment effect on the number of Turner networks is positive and significant. The merged systems increased their number of Turner Broadcasting networks between 0.29-0.44 networks more than the non-merged systems did. These results suggest that the merger either reduced vertical externalities or bargaining problems and achieved either an efficient input substitution or efficient level of trade between the upstream and downstream firms.

Most importantly, I found the statistically significant evidence of an efficiency effect on price. The average treatment effect on price per network is negative and significant at the 5-percent level except in the case of $M=4$. Although both groups seem to experience a decrease in the price per network during the sample periods, such a decrease is 13.5-20.8 cents more in the merged markets. This difference is quite significant if we consider the fact that the median license fee is about 10 cents. ${ }^{23}$

Another interesting result is that the treatment effects on non-Turner networks owned by Time Warner were positive and significant. Specifically, Comedy Central and Court TV increased their market shares by about 14-16 percent and 9-11 percent more in the merged markets than in the non-merged markets respectively.

The average treatment effect on penetration rates is not significant, although the sign supports the efficiency theories. One explanation for this insignificant result is that vertical integration simply has little effect on them. This may be the case for the basic service in particular (something we examine here) as basic service consists of affiliated and nonaffiliated networks. 


\subsection{The Foreclosure Effect}

If vertical integration is to facilitate monopolization in the upstream market, then integrated operators will tend to exclude program services, particularly those that directly rival their upstream affiliates. Here, I examine the average treatment effects on Turner Broadcasting's rival networks. I chose two or three networks in each of four genre: news, children programming, movies and entertainment. These correspond as rivals of CNN, the Cartoon Network, TCM and TNT/TBS respectively. Table 6 shows the average treatment effects on the rival networks. CNBC, Fox News Channel, MSNBC are news channels, the Disney Channel and Nickelodeon are children's channels, AMC, the Independent film channel and the Sci Fi Channel are movie channels, and Fox Family Channel, FX Network, and the Odyssey Network are entertainment channels.

As can be seen in the table, for each genre except news, I found a negative and significant effect for at least one rival network. Specifically, I found that the increase in the market share of the Disney Channel is about 10 to 11.5 percent lower for the merged markets than for the non-merged markets with a low significance level. Increases in the market shares of AMC, FX and Odyssey are, respectively, 12.0 to 15.1 percent, 5.9 to 8.4 percent, and 5.2 to 13.0 percent lower for the merged markets. This might suggest that the merged firm practiced foreclosure of these networks.

In addition, I found a positive and significant average treatment effect on the Sci Fi Channel. The reason for positive effect may be that this network is actually somewhat related to the new merged firm, Turner-Time-Warner. The Sci Fi channel is partially owned by Liberty Media, which is owned by TCI, which owns a share of Turner-Time-Warner.

Similar to the cases of Comedy Central and Court TV then, the merged systems seem to 
favor networks that are even partially affiliated with the new merged firm, Turner-TimeWarner, even if they are rival networks of Turner Broadcasting.

\subsection{Discussion}

The above results show that Time-Warner significantly favors its affiliated networks. Because more downstream markets owned by Time-Warner carried Turner Broadcasting networks after the merger, Turner Broadcasting networks could expand their national market shares significantly. The merger must have benefitted Turner Broadcasting significantly. Even the TBS Superstation, which already had 70.4 percent of the national television household market share in 1995 (Kagan Associate Inc. (2000), pp. 37), was additionally carried, thus increasing its market share due to the merger. These carriage results support the efficiency theories of vertical integration. The neoclassical efficiency theory shows that integration eliminates vertical externalities and promotes efficient input substitution, while the organizational economics-based efficiency theory argues that integration eliminates contractual hazards and thus brings about an efficient level of trade - consequently, trade between integrated upstream and downstream firms increases. Our results are consistent with this prediction.

The neoclassical efficiency theory predicts lower prices and higher sales in downstream markets. As is consistent with this theory, I found that the merged markets lowered the price per network to a greater extent than the non-merged markets. This constitutes new evidence of the efficiency effect, as previous studies did not find such an effect on prices. Unlike Waterman and Weiss (1996), however, I did not find that vertical integration had a positive effect on penetration rates. This may be because the 'service' studied here consists 
of a bundle of affiliated and non-affiliated networks; hence, if the proportion of integrated networks in a basic service is small, the related efficiency gains may have little impact on final sales. ${ }^{24}$

In order to see the network level effect, I also estimated average treatment effect on the number of subscribers for each network rather than for basic services. That is, if a Turner network is carried as part of a basic service, I count the number of subscribers subscribing to only the basic service; if it is carried as part of an extended basic service, I then count the number of subscribers subscribing to the extended service. This gives me the number of subscribers who actually have access to this network rather than the number of total subscribers who subscribe to a basic service and extended basic services, as in the earlier section. If the merger promotes the efficiency of the network-for example, by promoting the downstream service - then we should see the number of subscribers who have access to the network increase in such markets. The results using 10 matches are shown in Table 7. From this estimation, I find positive and significant average treatment effects for the merger on the number of subscribers who have access to the Cartoon Network and Turner Classic Movies. This may suggest that vertical integration led to an increased downstream sales effort for the two relatively new networks, the Cartoon Network and Turner Classic Movies.

Both Chipty (2001) and Waterman and Weiss (1996) find evidence of foreclosure - that is, they show as an evidence of exclusionary behavior that vertically integrated cable systems carry rival networks less than non-integrated cable systems do. Here, I also find the negative treatment effects on several rival networks. However, it may be questionable to describe this phenomenon as exclusionary behavior, inasmuch as the rival networks seem to have increased their market shares in both the merged and non- merged markets. The negative treatment 
effects on the rival networks merely show that such increases in market shares are lower in the merged markets. It is thus unlikely that this phenomenon constitutes exclusionary behavior for the purpose of monopolization.

Rather than constituting a type of exclusionary behavior, the negative treatment effects on the rival networks might be explained as the result of substitution effects. That is, as in efficiency theory, integrated downstream markets substitute more towards affiliated inputs. Hence "other potential suppliers are in some sense 'foreclosed' from providing those input supplied to the vertically integrated firm" (Joskow (2005)). In fact, Joskow states that it is important to distinguish between'a naive view' of a market foreclosure that is sometimes associated with vertical integration because of input substitution, and the issues that arise as a result of the strategic use of vertical integration to soften competition in order to raise prices. The phenomena seen here seems to fit the former case.

Even if this constitutes an anti-competitive strategic practice, the foreclosure effect, if any, is dominated by the efficiency effect. Along with the results of Chipty (2001) and Waterman and Weiss (1996), my findings suggest that there is little evidence that consumers are harmed by the vertical integration.

Neither these previous studies nor mine, however, examine the effect of vertical integration as a barrier to entry; hence, it may be too early to conclude that foreclosure does not have a negative effect in the industry. By favoring its own children network, the Cartoon Network, and excluding rival networks, the merged firm might have formed a barrier against new children networks entering in Time Warner's downstream markets. In fact, my dataset shows that no Time Warner markets carries a new children's network, Toon Disney (that started in 1998), during the examined period, 31 non-integrated markets with 513,389 sub- 
scribers carry it. ${ }^{25}$ Furthermore, the FCC (2001) states that only a few of the 72 planned network services counted in the 1999 Report have actually been launched during the past year (and continue to appear); others have been aborted for various reasons. Such a fact may suggest a difficulty in entering, and may be related to the increased amount of integration in the industry. Further research should be conducted to examine this issue.

\section{Conclusion}

In this study, I examine the impact of the vertical merger between Turner Broadcasting and Time Warner on the outcomes of the downstream market. Because selection on whether or not to participate in this merger is non-random, I adopt a non-experimental estimation strategy - the bias-adjusted matching method recently developed by Abadie and Imbens (2002). I modify it by incorporating the difference-in-differences method to mitigate the 'selection on unobservables' problem. For the matching variables, I use nine variables in the participation equation and four variables in the outcome equations. The variables in the participation equation determine whether a system was owned by Time-Warner in 1995 (and was thus involved in Time-Warner's merger with Turner Broadcasting); they include owner's size, population density, the number of homes covered locally, channel capacity, and the miles of plant all evaluated at the period of pre-treatment. The variables in the outcome equations are the differenced demand factors exogenous to the merger, and include changes in income, the percentage of young, the percentage of non-whites, and population density.

The results show that there was a significant efficiency gain from the merger. The merged systems were found to carry Turner networks more frequently than the non-merged systems. Additionally, there was a larger price decrease in the merged markets. Finally, the two new 
networks, the Cartoon Network and Turner Classic Movies, increased their subscribers more in the merged markets.

There is also evidence that the increase in the market shares of the rival networks were lower in the merged markets. Such negative treatment effects, however, should be explained as resulting from substitution effects rather than from the exclusionary behavior of foreclosure.

\section{References}

[1] Abadie, Alberto, and Guido W. Imbens, "Simple and Bias-Corrected Matching Estimators for Average Treatment Effects," NBER Technical Working Paper no. 283 (2002).

[2] Abadie, Alberto, David Drukker, Jane Leber Herr, and Guido W. Imbens , "Implementing Matching Estimators for Average Treatment Effects in Stata," The Stat Journal 1 (2001), 1-18.

[3] Aghion, Philippe, and Patrick Bolton, "Contracts as a Barrier to Entry," American Economic Review 77:3 (1987), 388-401.

[4] Chipty, Tasneem, "Vertical Integration, Market Foreclosure, and Consumer Welfare in the Cable Television Industry," American Economic Review 91:3 (2001), 428-451.

[5] Federal Communications Commission, "Seventh Annual Report," (2001).

[6] Gilbert, Richard, and Justine Hastings, "Market Power, Vertical Integration and the Wholesale Price of Gasoline," Journal of Industrial Economics 53:4 (2005), 469-492. 
[7] Hart, Oliver, and Jean Tirole, "Vertical Integration and Market Foreclosure," Brookings Papers on Economic Activity Special Issue (1990), 205-276.

[8] Heckman, James J., Hidehiko Ichimura, and Petra E. Todd, "Matching as an Econometric Evaluation Estimator: Evidence from Evaluating a Job Training Programme," Review of Economic Studies 64:4 (1997), 605-654.

[9] Heckman, James J., Hidehiko Ichimura, and Petra E. Todd, "Matching as an Econometric Evaluation Estimator," Review of Economic Studies 65:2 (1998), 261-294.

[10] Imbens, Guido W., "Nonparametric Estimation of Average Treatment Effects Under Exogeneity: A Review," Review of Economics and Statistics 86:1 (2004), 4-29.

[11] Joskow, Paul L., "Vertical Integration," in Claude Menard and Mary M. Shirley (Eds.), Handbook of New Institutional Economics (Dordrecht and New York: Springer 2005, $319-48)$.

[12] Marvel, Howard P., "Exclusive Dealing," Journal of Law and Economics 25:1 (1982), $1-25$

[13] Moffitt, Robert A., "Introduction to the Symposium on the Econometrics of Matching," Review of Economics and Statistics 86:1 (2004), 1-3.

[14] Ordover, Janusz A., Garth Saloner, and Steven C. Salope, "Equilibrium Vertical Foreclosure," American Economic Review 80:1 (1990), 127-142.

[15] Paul Kagan Associates, Kagan's Economics of Basic Cable Networks (Carmel, Calif: Paul Kagan Associates, 2000). 
[16] Tirole, Jean, The Theory of Industrial Organization (Cambridge, MA:MIT Press, 1988).

[17] U.S. Bureau of the Census, Department of Commerce, City and County Data Book (Washington, DC:U.S. Government Printing Office, Various years).

[18] Vita, Michael G., "Regulatory Restrictions on Vertical Integration and Control: The Competitive Impact of Gasoline Divorcement Policies," Journal of Regulatory Economics 18:3 (2000), 217-233.

[19] Warren Publishing, Television and Cable Factbook (Washington, DC:Warren Publishing, 1996, 2001).

[20] Waterman, David, and Andrew A. Weiss, "The Effects of Vertical Integration Between Cable Television Systems and Pay Cable Networks," Journal of Econometrics 72:1-2 (1996), 357-395. 


\section{Notes}

${ }^{1}$ It was implemented by the Federal Communications Commission (the FCC). It limits the number of channels a cable system can use to exhibit programming in which it has a 5 percent or greater equity interest.

${ }^{2}$ The numbers in this subsection are taken from FCC (2003). Specifically, in 2003, 110 of the 330 existing satellite-delivered national programming networks were vertically integrated with at least one cable MSO.

${ }^{3}$ Three famous illustrations of vertical externality, which can fit to the situation of the cable industry, are: Double Marginalization, Downstream Moral Hazard, and Input Substitution. See Tirole (1988, Chapter 4).

${ }^{4}$ Upstream foreclosure is also an issue in this industry. Cable distributors other than cable operators (such as satellite television) claim that vertical integration between cable programming firms and cable operators makes it difficult for them to carry integrated networks.

${ }^{5}$ See, for example, a model called Scarce Needs in Hart and Tirole (1990). It explains how, with two upstream and two downstream firms, downstream foreclosure due to vertical integration may induce exits of the rival upstream firm and the rival downstream firm.

${ }^{6}$ On the other hand, much more work has been done examining the causes of vertical integration. These studies have focused on testing organizational economics-based theories because the related prediction is clear: more vertical integration should be observed in industries where more specific assets are needed. (See Joskow (2005) for the review of literature.)

${ }^{7}$ Under the agreement, the TCI Chairman would cap his interest in the merged company at 9.2 percent, spin off TCI shares to the company's Liberty Media subsidiary, and turn over 
voting control of his company's shares to Time Warner. In addition, Time-Warner was also to agree in writing that it would not discriminate against its competitors, and was required to offer at least half of its cable subscribers an independent all-news channel to compete with CNN. Furthermore, TCI's 20-year deal to carry Time-Warner-Turner programming at a 15 percent discount was canceled. New contracts with a maximum length of five years were to be renegotiated six months after the merger was consummated.

${ }^{8} \mathrm{~A}$ five-year lag is used because the average contract term between a cable program service and a cable operator is three years, and cable operators may not be able to change their program offerings immediately after mergers. This time period is also desirable because during this period, there was no other large vertical merger such as might have affected the treated and controlled groups differently.

${ }^{9}$ These are the top eight states in terms of the percentage of merged systems among all systems in a state.

${ }^{10}$ The two networks, Comedy Central and Courtroom Television Network, are not Turner Broadcasting networks, but are partially owned by Time Warner. In that sense, these networks are affiliated to the new merged firm, Turner-Time Warner.

${ }^{11}$ An indicator variable for network $N$ in market $m$ at time $t$ takes the value 1 if network $N$ is carried in market $m$ at time $t$. The mean value of an indicator variable at time $t$ thus express the national market share of that network. Consequently, the average of the difference in the indicator variables for the two time points indicates the change in the national market share of the network.

${ }^{12}$ The model is available on request.

${ }^{13}$ Specifically, the proxies for these factors are: 1) household income, number of homes 
covered locally, percentage of young viewership, and percentage of non-white viewership as demographic variables, 2) system's age and population density as system efficiency, 3) number of homes covered locally, channel capacity, and miles of plant as system size, and 4) total number of homes covered by an owner as owner characteristics.

${ }^{14}$ To implement the matching procedure, we cannot use, as the matching variables, variables that depend on whether or not treatment is received. The $Z$ variables can clear this criteria because they are pre-merger variables. However, some differenced variables (i.e., $V$ ) should be used with caution. Specifically, system and owner characteristics such as changes in the number of homes covered, in channel capacity and in the miles of plant may depend on whether the system is involved with the merger, as the merger may enable systems to invest in improving conditions of these variables. Consequently, I exclude these variables from possible use as matching variables. Demographic variables, conversely, are exogenous to merger status, and can thus be used as matching variables.

${ }^{15} \mathrm{~A}$ cable operator is an owner of cable systems. Since the decision to vertically integrate is made between a program service provider and a cable operator, each system in a local market is automatically integrated if its owner becomes integrated. Consequently, for each system, the integration decision is exogenous.

${ }^{16}$ As discussed in the previous subsection, I assume that the decision of an MSO to purchase a local cable system depends on the profitability of the cable system, something which affects market outcomes.

${ }^{17}$ In practice, matching estimators are preferred in situations where the main interest is in the average treatment effect for the treated, and there is a large reservoir of potential controls (Imbens (2004), pp13). 
${ }^{18}$ Abadie and Imbens (2002) show that with $k$ continuous covariates, the estimator will have a term corresponding to the matching discrepancies (the difference in covariates between the matched units and their matches) of the order $O_{p}\left(N^{-1 / k}\right)$.

${ }^{19}$ Although the large reservoir of potential controls may mitigate this bias - that is, in an asymptotic sequence, the number of potential controls increases faster than the number of treated units, thus causing the bias to disappear (see Imbens (2004) pp 14).

${ }^{20}$ In practice, bootstrapping is often used to calculate standard error. However, there is no theoretical justification for using the bootstrapping method for a variance estimation of matching estimators.

${ }^{21}$ In general, the matching estimator is not efficient (see Abadie and Imbens (2002)).

${ }^{22}$ though there is not a theoretical justification and this may not be always the case.

${ }^{23}$ See the Federal Communications Commission's "Seventh Annual Report" (2001).

${ }^{24}$ On the other hand, Waterman and Weiss (1996) examined premium services, which are sold independently.

${ }^{25}$ Unfortunately, the number of observations was too small for an estimation. 


\begin{tabular}{|c|c|}
\hline Dependent Variables & Definition (Difference between 1995 and 2000) \\
\hline \multicolumn{2}{|l|}{ Outcome variables } \\
\hline Change in Turner Number & The number of Turner Broadcasting networks in the service \\
\hline Change in Non-Turner Number & The number of non-Turner Broadcasting networks in the service \\
\hline Change in Fee per Network & The monthly subscription fee per networks \\
\hline Change in Penetration Rate & The penetration rate \\
\hline Turner networks & (The change in the national market share from 1995 to 2000) \\
\hline Change in Prob(TBS) & TBS Superstation \\
\hline Change in Prob(Cartoon) & The Cartoon Network \\
\hline Change in Prob(CNN) & $\mathrm{CNN}$ \\
\hline Change in Prob(TCM) & Turner Classic Movies \\
\hline Change in Prob(TNT) & Turner Network TV \\
\hline Time Warner Networks & (The change in the national market share from 1995 to 2000) \\
\hline Change in Prob(Comedy) & Comedy Central \\
\hline Change in Prob(CourtTV) & Courtroom Television Network \\
\hline Rival Networks & (The change in the national market share from 1995 to 2000) \\
\hline (News) & (As rival networks to $\mathrm{CNN}$ ) \\
\hline Change in Prob(CNBC) & $\mathrm{CNBC}$ \\
\hline Change in Prob(Fox News) & Fox News Channel \\
\hline Change in Prob(MSNBC) & MSNBC \\
\hline (Children) & (As rival networks to the Cartoon Network) \\
\hline Change in Prob(Disney) & The Disney Channel \\
\hline Change in Prob(Nickelodeon) & Nickelodeon \\
\hline (Movie) & (As rival networks to TCM) \\
\hline Change in Prob(AMC) & American Movie Classics \\
\hline Change in Prob(Independent) & The Independent Film Channel \\
\hline Change in Prob(SciFi) & The Sci Fi Channel \\
\hline (Entertainment) & (As rival networks to TNT and TBS Superstation) \\
\hline Change in Prob(FoxFamily) & The Fox family Channel \\
\hline Change in Prob(FX) & FX \\
\hline Change in Prob(Odyssey) & Odyssey Network \\
\hline
\end{tabular}

Table 1: Dependent variable definitions 


\begin{tabular}{|c|c|c|c|c|c|c|}
\hline & Mean & S.D. & Treated & Control & \multicolumn{2}{|c|}{ DID } \\
\hline Change in Turner Number & 0.581 & 1.089 & 0.912 & 0.467 & 0.445 & $* * *$ \\
\hline Change in Non-Turner Number & 14.654 & 10.458 & 16.976 & 13.826 & 3.150 & $* * *$ \\
\hline Change in Fee per Network & -0.425 & 1.090 & -0.383 & -0.440 & 0.057 & \\
\hline Change in Penetration Rate & 0.457 & 6.178 & 0.510 & 0.440 & 0.070 & \\
\hline Change in Prob(TBS) & 0.058 & 0.350 & 0.106 & 0.041 & 0.065 & $* *$ \\
\hline Change in Prob(Cartoon) & 0.182 & 0.398 & 0.315 & 0.137 & 0.179 & $* * *$ \\
\hline Change in Prob(CNN) & 0.006 & 0.307 & -0.006 & 0.010 & -0.016 & \\
\hline Change in Prob(TCM) & 0.176 & 0.391 & 0.255 & 0.149 & 0.106 & $* * *$ \\
\hline Change in Prob(TNT) & 0.101 & 0.362 & 0.081 & 0.108 & -0.026 & \\
\hline Change in Prob(Comedy) & 0.315 & 0.468 & 0.445 & 0.271 & 0.175 & $* * *$ \\
\hline Change in Prob(CourtTV) & 0.081 & 0.302 & 0.194 & 0.042 & 0.152 & $* * *$ \\
\hline Change in Prob(CNBC) & 0.029 & 0.441 & 0.055 & 0.020 & 0.035 & \\
\hline Change in Prob(Fox News) & 0.109 & 0.314 & 0.170 & 0.088 & 0.082 & $* * *$ \\
\hline Change in Prob(MSNBC) & 0.166 & 0.376 & 0.276 & 0.128 & 0.148 & $* * *$ \\
\hline Change in Prob(Disney) & 0.229 & 0.426 & 0.064 & 0.285 & -0.222 & $* * *$ \\
\hline Change in Prob(Nickelodeon) & 0.221 & 0.437 & 0.239 & 0.215 & 0.024 & \\
\hline Change in Prob(AMC) & 0.568 & 0.509 & 0.624 & 0.549 & 0.075 & $* * *$ \\
\hline Change in Prob(Independent) & 0.002 & 0.039 & 0.003 & 0.001 & 0.002 & \\
\hline Change in Prob(Scifi) & 0.203 & 0.423 & 0.248 & 0.187 & 0.061 & $* *$ \\
\hline Change in Prob(FoxFamily) & 0.043 & 0.273 & 0.048 & 0.042 & 0.006 & \\
\hline Change in Prob(FX) & 0.091 & 0.293 & 0.118 & 0.082 & 0.036 & $* *$ \\
\hline Change in Prob(Odyssey) & 0.140 & 0.349 & 0.215 & 0.114 & 0.101 & $* * *$ \\
\hline
\end{tabular}

Stars refer to the significance of a t-test on the means.

$*$ =significant at the $10 \%$ level, ${ }^{* *}=$ significant at the $5 \%$ level, ${ }^{* * *}=$ significant at the $1 \%$ level

Table 2: Dependent variables 


\begin{tabular}{l|l}
\hline The variables in the participation equation $(Z)$ \\
\hline \hline Owner size & Total number of homes covered by an owner in 1995 \\
Income & Median household income in 1992 \\
Young & Percentage of population between age 5 and 15 in 1992 \\
Non White & Percentage of population non-white in 1992 \\
Density & Population density in 1992 \\
Age & Number of years since franchise began in 1995 \\
Home passed & Number of homes covered locally in 1995 \\
Capacity & Channel capacity in 1995 \\
Plant & Miles of plant in 1995 \\
\hline The variables in the outcome equations $(V)$ \\
\hline \hline Change in Income & Change from 1992 to 2000 \\
Change in Young & Change from 1992 to 2000 \\
Change in Non White & Change from 1992 to 2000 \\
Change in Density & Change from 1992 to 2000 \\
\hline
\end{tabular}

Table 3: Matching variable definitions 


\begin{tabular}{|c|c|c|c|c|c|}
\hline & Mean & S.D. & Treatment & \multicolumn{2}{|c|}{ Control } \\
\hline Ownersize & $1,191,758$ & 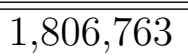 & $2,761,317$ & (668,070 & **** \\
\hline Income & $32,238.02$ & $7,133.73$ & $33,116.51$ & $31,944.62$ & $* * *$ \\
\hline Young & 18.33 & 2.22 & 18.39 & 18.31 & \\
\hline Non white & 11.82 & 12.34 & 12.76 & 11.51 & $* * *$ \\
\hline Density & 391.22 & 1938.97 & 473.86 & 363.62 & $* *$ \\
\hline Age & 17.73 & 9.66 & 20.83 & 16.60 & $* * *$ \\
\hline Home passed & $18,242.24$ & $63,228.11$ & $30,712.34$ & $13,997.72$ & $* * *$ \\
\hline Capacity & 41.86 & 14.71 & 42.82 & 41.52 & $* * *$ \\
\hline Plant & 187.47 & 411.28 & 308.92 & 146.95 & $* * *$ \\
\hline Change in income & 3304.23 & 2487.23 & 3283.59 & 3311.12 & \\
\hline Change in young & 0.03 & 1.24 & 0.11 & 0.00 & $* * *$ \\
\hline Change in non white & 0.71 & 2.80 & 0.43 & 0.80 & $* * *$ \\
\hline Change in density & 36.12 & 409.49 & 70.29 & 24.71 & $* * *$ \\
\hline Number of markets & & & 348 & 1,043 & \\
\hline
\end{tabular}

Stars refer to the significance of a t-test on the means. ${ }^{*}=$ significant at the $10 \%$ level, ${ }^{* *}=$ significant at the $5 \%$ level, ${ }^{* * *}=$ significant at the $1 \%$ level.

Table 4: Summary Statistics of Matching Variables 


\begin{tabular}{|c|c|c|c|c|c|c|c|c|}
\hline & \multicolumn{2}{|c|}{$M=4$} & \multicolumn{2}{|c|}{$M=6$} & \multicolumn{2}{|c|}{$M=8$} & \multicolumn{2}{|c|}{$M=10$} \\
\hline Change in & 0.289 & *** & 0.385 & **** & 0.427 & $* * *$ & 0.444 & $* * *$ \\
\hline Turner Number & $(0.140)$ & & $(0.146)$ & & $(0.140)$ & & $(0.145)$ & \\
\hline Change in & -0.892 & & -0.763 & & -0.759 & & -0.754 & \\
\hline Non-Turner Number & $(1.224)$ & & $(1.248)$ & & $(1.259)$ & & $(1.241)$ & \\
\hline Change in & -0.134 & & -0.167 & $* *$ & -0.193 & $* *$ & -0.208 & $* *$ \\
\hline Fee per Network & $(0.094)$ & & $(0.082)$ & & $(0.080)$ & & $(0.083)$ & \\
\hline Change in & 0.455 & & 0.427 & & 0.432 & & 0.452 & \\
\hline Penetration Rate & $(0.596)$ & & $(0.574)$ & & $(0.562)$ & & $(0.629)$ & \\
\hline Change in & 0.113 & $* *$ & 0.118 & $* *$ & 0.127 & $* * *$ & 0.125 & $* *$ \\
\hline Prob(TBS) & $(0.048)$ & & $(0.046)$ & & $(0.046)$ & & $(0.046)$ & \\
\hline Change in & 0.043 & & 0.058 & & 0.044 & & 0.041 & \\
\hline Prob(Cartoon) & $(0.055)$ & & $(0.058)$ & & $(0.053)$ & & $(0.052)$ & \\
\hline Change in & -0.083 & $* *$ & -0.069 & $* *$ & -0.056 & $*$ & -0.055 & $*$ \\
\hline $\operatorname{Prob}(\mathrm{CNN})$ & $(0.035)$ & & $(0.032)$ & & $(0.031)$ & & $(0.031)$ & \\
\hline Change in & 0.093 & $* *$ & 0.126 & $* *$ & 0.137 & $* * *$ & 0.145 & $* * *$ \\
\hline $\operatorname{Prob}(\mathrm{TCM})$ & $(0.047)$ & & $(0.049)$ & & $(0.050)$ & & $(0.052)$ & \\
\hline Change in & -0.005 & & 0.021 & & 0.043 & & 0.052 & \\
\hline $\operatorname{Prob}(\mathrm{TNT})$ & $(0.044)$ & & $(0.044)$ & & $(0.043)$ & & $(0.052)$ & \\
\hline Change in & 0.141 & $* * *$ & 0.162 & $* * *$ & 0.154 & $* * *$ & 0.149 & $* * *$ \\
\hline Prob(Comedy) & $(0.050)$ & & $(0.050)$ & & $(0.047)$ & & $(0.045)$ & \\
\hline Change in & 0.088 & $* *$ & 0.108 & $* * *$ & 0.107 & $* * *$ & 0.101 & $* * *$ \\
\hline Prob(Court TV) & $(0.038)$ & & $(0.038)$ & & $(0.037)$ & & $(0.037)$ & \\
\hline
\end{tabular}

Note: $\mathrm{M}$ is the number of matches.

Weighting matrix: inverse matrix.

Matching variables: ownersize, income, young, non-white, density, age, homepassed, capacity, plant, change in income, change in young, change in non-white, change in density. Bias adjusted variables: all the matching variables.

Stars refer to the significance level $*=10 \%$ level, $* *=5 \%$ level, $* * *=1 \%$ level.

Table 5: Average Treatment Effects for the Treated 


\begin{tabular}{|c|c|c|c|c|c|c|c|c|}
\hline & \multicolumn{2}{|c|}{$M=4$} & \multicolumn{2}{|c|}{$M=6$} & \multicolumn{2}{|c|}{$M=8$} & \multicolumn{2}{|c|}{$M=10$} \\
\hline Change in & -0.019 & & 0.019 & & 0.031 & & 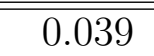 & \\
\hline $\operatorname{Prob}(\mathrm{CNBC})$ & $(0.047)$ & & $(0.047)$ & & $(0.045)$ & & $(0.044)$ & \\
\hline Change in & -0.037 & & -0.063 & & -0.084 & $* *$ & -0.089 & $* *$ \\
\hline Prob(Fox News) & $(0.044)$ & & $(0.043)$ & & $(0.041)$ & & $(0.040)$ & \\
\hline Change in & 0.038 & & 0.023 & & 0.004 & & -0.003 & \\
\hline Prob(MSNBC) & $(0.043)$ & & $(0.041)$ & & $(0.042)$ & & $(0.041)$ & \\
\hline Change in & -0.115 & $* *$ & -0.100 & $*$ & -0.102 & $*$ & -0.104 & $*$ \\
\hline Prob(Disney) & $(0.052)$ & & $(0.055)$ & & $(0.059)$ & & $(0.060)$ & \\
\hline Change in & -0.019 & & -0.017 & & 0.000 & & -0.003 & \\
\hline Prob(Nickelodeon) & $(0.049)$ & & $(0.050)$ & & $(0.046)$ & & $(0.045)$ & \\
\hline Change in & -0.120 & $* *$ & -0.126 & $* * *$ & -0.141 & $* * *$ & -0.151 & $* * *$ \\
\hline $\operatorname{Prob}(\mathrm{AMC})$ & $(0.051)$ & & $(0.047)$ & & $(0.047)$ & & $(0.047)$ & \\
\hline Change in & 0.003 & & 0.003 & & 0.003 & & 0.003 & \\
\hline Prob(Independent) & $(0.006)$ & & $(0.006)$ & & $(0.006)$ & & $(0.005)$ & \\
\hline Change in & 0.048 & & 0.085 & $*$ & 0.085 & $*$ & 0.090 & $* *$ \\
\hline Prob(Scifi) & $(0.047)$ & & $(0.046)$ & & $(0.045)$ & & $(0.044)$ & \\
\hline Change in & 0.041 & & 0.042 & & 0.055 & & 0.055 & \\
\hline Prob(FoxFamily) & $(0.036)$ & & $(0.036)$ & & $(0.035)$ & & $(0.036)$ & \\
\hline Change in & -0.059 & $*$ & -0.065 & $*$ & -0.079 & $* *$ & -0.084 & $* *$ \\
\hline $\operatorname{Prob}(\mathrm{FX})$ & $(0.035)$ & & $(0.035)$ & & $(0.036)$ & & $(0.036)$ & \\
\hline Change in & -0.052 & & -0.100 & $* *$ & -0.121 & $* * *$ & -0.130 & $* * *$ \\
\hline Prob(Odyssey) & $(0.044)$ & & $(0.045)$ & & $(0.047)$ & & $(0.004)$ & \\
\hline
\end{tabular}

Note: $\mathrm{M}$ is the number of matches.

Weighting matrix: inverse matrix.

Matching variables: ownersize, income, young, non-white, density, age, homepassed,

capacity, plant, change in income, change in young, change in non-white, change in density.

Bias adjusted variables: all the matching variables.

Stars refer to the significance level $*=10 \%$ level, $* *=5 \%$ level, $* * *=1 \%$ level.

Table 6: (Continued) 


\begin{tabular}{l|rr}
\hline & $\mathbf{( M = 1 0 )}$ \\
\hline \hline Change in sub(TBS) & 1572.57 & \\
& $(6159.30)$ & \\
Change in sub(Toon) & 10879.42 & $*$ \\
& $(5789.94)$ & \\
Change in sub(CNN) & 5096.34 & \\
& $(3397.37)$ & \\
Change in sub(TCM) & 11318.09 & $* *$ \\
& $(4667.34)$ & \\
Change in sub(TNT) & 2789.32 & \\
& $(4513.22)$ & \\
\hline
\end{tabular}

Table 7: Average Treatment Effects for the Treated on the number of subscribers for each network 